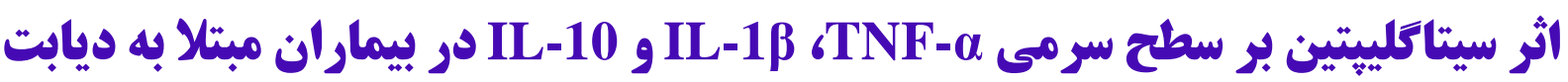

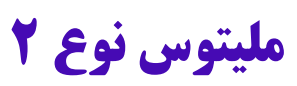

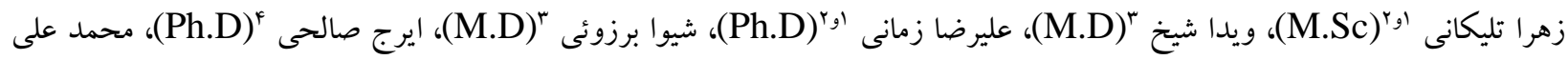 \\ (Ph.D) اميرزر

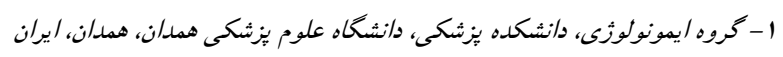

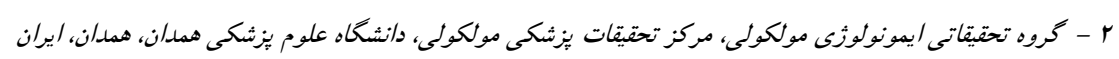

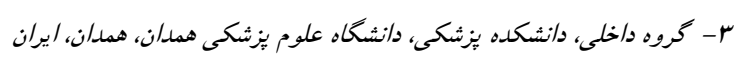

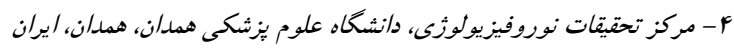

\section{هكبر}

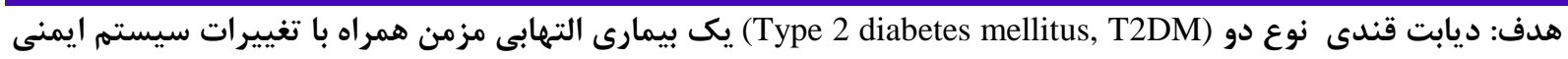

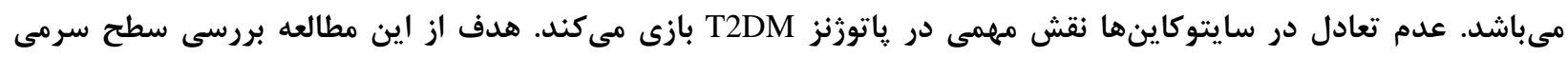
سايتوكاينهاى TNF-

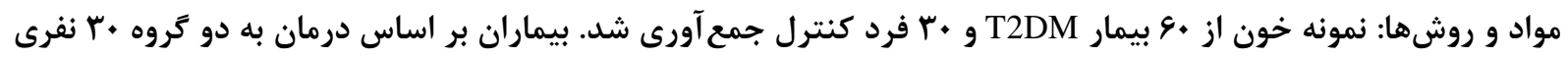

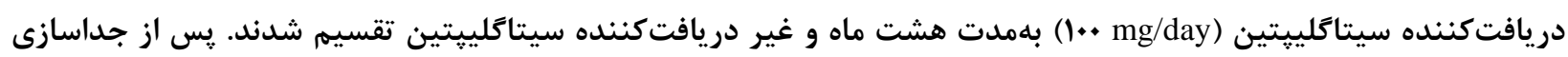

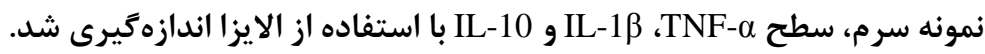
يافته ها: سطح سر مى TNF-

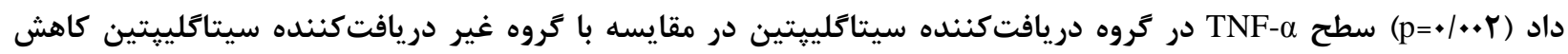

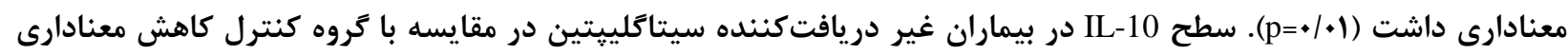

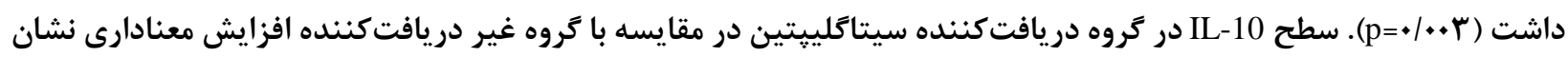

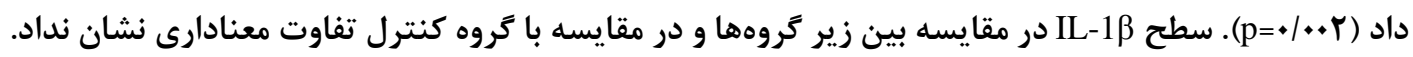

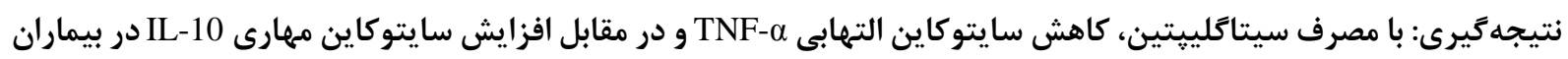

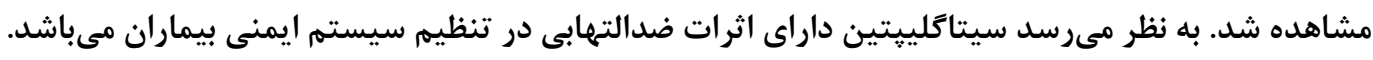

وازههاى كليدى: ديابت مليتوس نوع دو، سيتاكلييتين، سايتوكاين، اينترلوكين •ا، اينترلوكين ا بتا، فاكتور نكروزدهنده تومور

يروتئينهاى فاز حاد از جمله شاخصهاى نشاندهنده بيشرفت

$$
\text { التهاب در T2DM مىباشند [ه، 4]. }
$$

سايتوكاين TNF- $\alpha$ (Tumor necrosis factorتوسط لنفوسيتهاى T و ماكروفازها توليد مىشود و باعث ايجاد

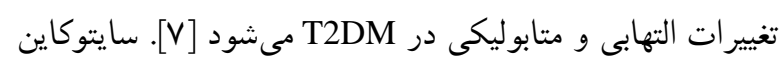

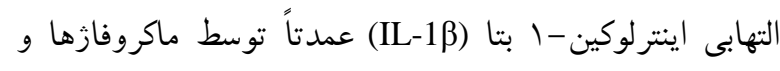

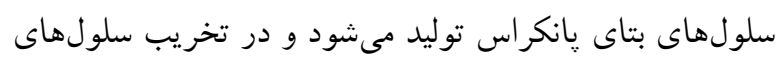

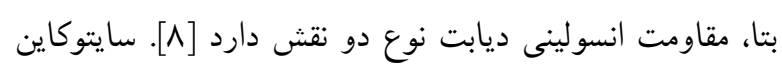

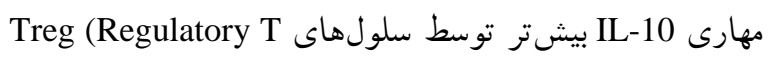

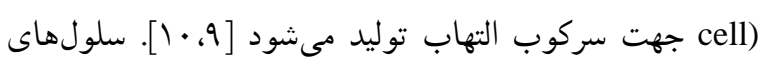

\section{مقدمه}

(Type 2 diabetes mellitus, ديابت قندى نوع دون يكى اختلال متابوليكى مزمن است كه افزايش قند خون T2DM)

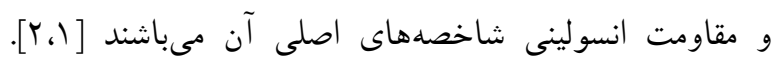

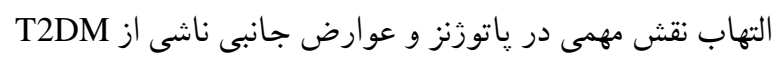

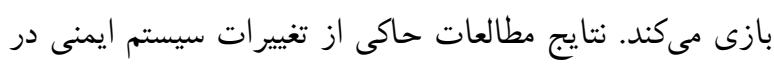

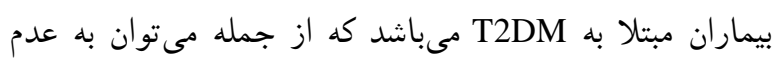

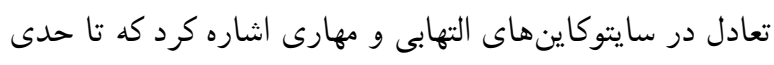

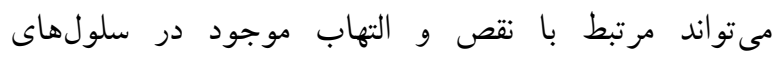

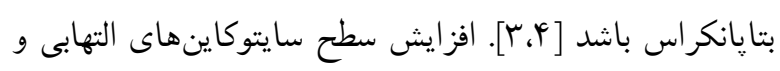


نمونههاى انسانى رعايت گرديد. در اين مطالعه • 4 بيمار مبتلا به

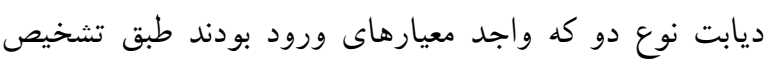

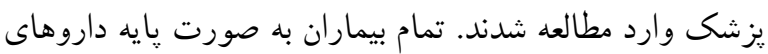
متفورمين با دوز mg/day

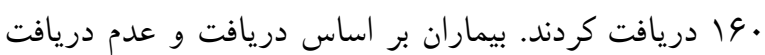

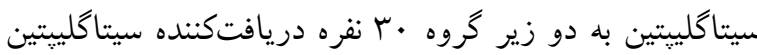
(Sitagliptin-) و غير دريافتكننده سيتاكليبيتين (Sitagliptin+) تقسيم شدند. بيماران دريافتكننده سيتاًكليبتين، به مدت هشت

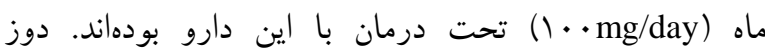
داروهاى فوقالذكر طبق نظر يزشك مربوطه و با توجه به علايم

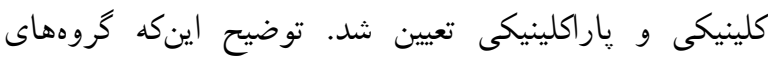

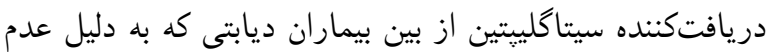
كنترل مناسب قند خون بلهوسيله داروهاى متفورمين و كلى

كلازيد كانديد دريافت سيتاًكليبين بودند وارد مطالعه شدند. معيارهاى ورود: () تشخيص بيمارى ديابت توسط يز شيك American Diabetes Association متخصص بر اساس معيار

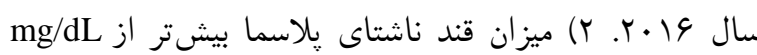

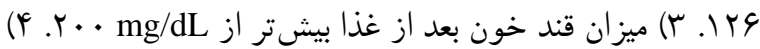

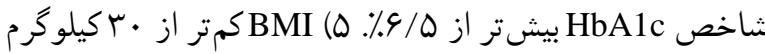

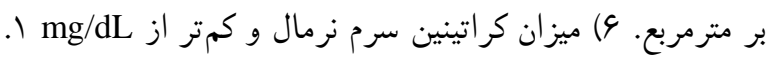

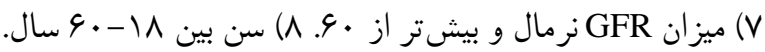

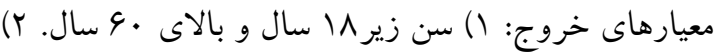

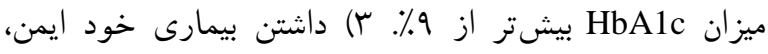

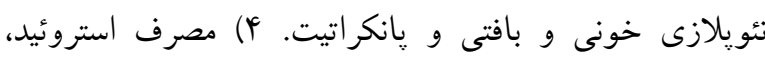
انسولين و داروهاى مهاركننده سيستم ايمنى. ه) داشتن نفروياتى كليوى و يا ريتينوياتى. 9) مصرف الكل و و سيخار.

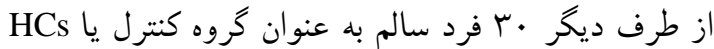
بعد از معاينه بالينى و آزمايشگاهى توسط بزشك، در صورت نداشتن بيمارى ديابت بـاني

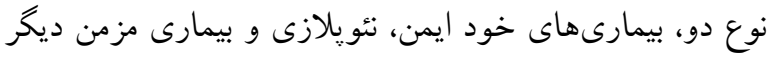

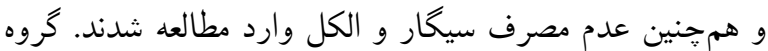

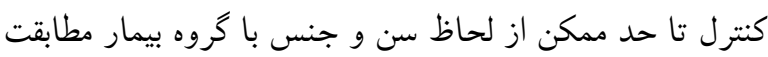

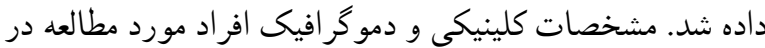
جدول آ آورده شده است.

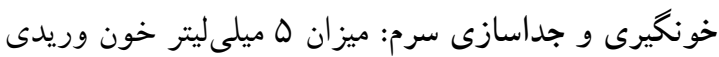

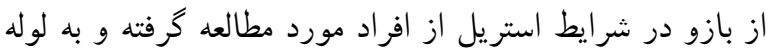

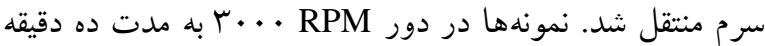

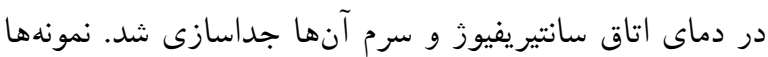

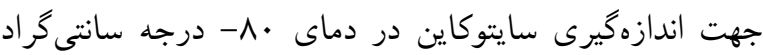

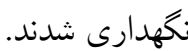

اندازهيرى سايتو كاين: سطح سرمى سايتوكاينهاى IL-10 (ELISA MAX ${ }^{\mathrm{TM}}$ Deluxe, Sensitivity: $2 \mathrm{pg} / \mathrm{mL}$,
CD4+(T helper cells) كمكىT Treg ير رده سلولهاىT)

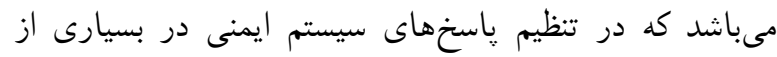
بيمارىهاى التهابى مانند ديابت نوع دو نقش دارند [ [IY.II]

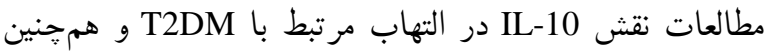

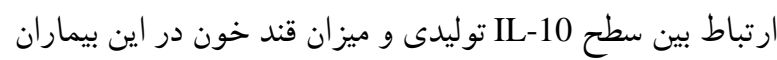

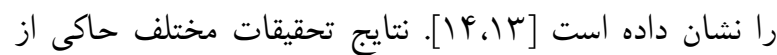
افزايش فاكتورهاى التهابى مانند CRP (C-reactive T2DM د IL-17 IFN- $\gamma$ (Interferon gamma) ،protein) مىباشد [19،19]. از سوى ديخر عدم تعادل بين زير خروههاى (19)

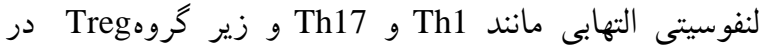
Tد2DM ديده شده است [IV] تجويز داروهاى روتين آنتىديابتيك مانند متفورمين و واليدال كليكلازيد به عنوان خط اول درمانى اين بيمارى مطرح است كه

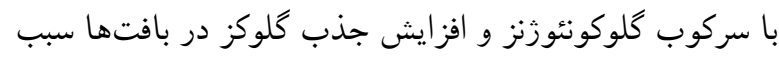

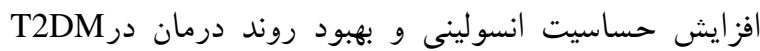

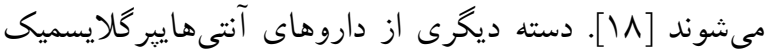

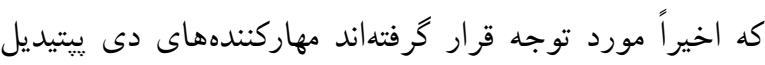
يبتيداز - أ مىباشند كه مهمترين آنها سيتاكليبتين (Sitagliptin)

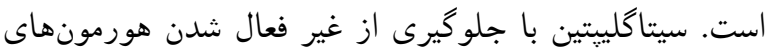

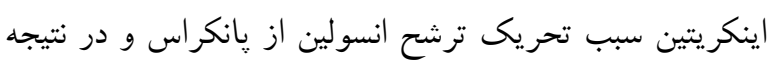
كاهش غلظت كلوكز خون مىشود [19]. تجويز سيتاگليبيتين IFN- $\gamma$ باعث كاهش سطح سرمى سايتوكاينهاى التهابى مانت

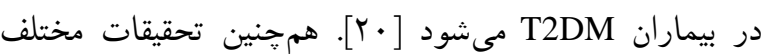
حاكى از كاهش فاكتورهاى التهابى مانند CRP در اثر مصرف

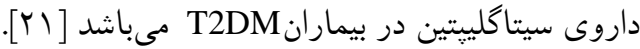

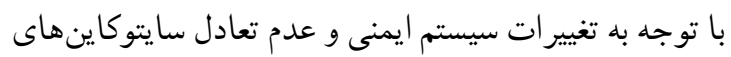

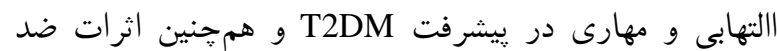

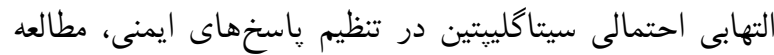

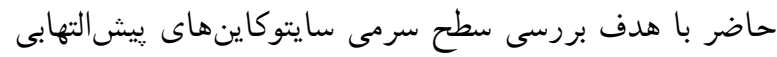
IL-13 TNF- $\alpha$

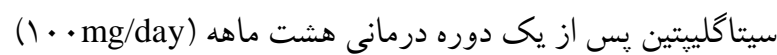

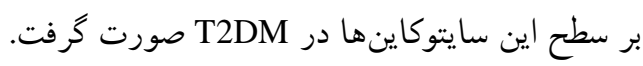

\section{مواد و روشهها}

جامعه و نمونه يُزوهش: اين مطالعه مورد-شاهدى پِ از از تصويب در كميته اخلاق دانشخاه علوم يزشكى همدان با كد بردان

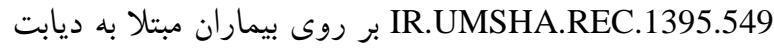
نوع دو مراجعهكنده به بيمارستان شهيد بهشتى انجام شد.

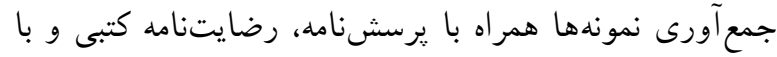

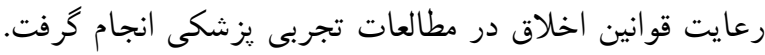

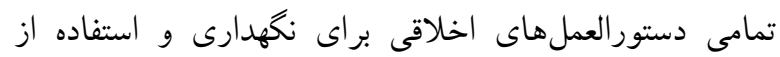


دقيقه بر روى شيكر در دماى اتاق انكوبه شد. بعد از انجام

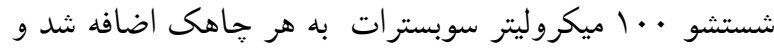
به مدت · r دقيقه در تاريكى نخهدارى شد. صد ميكروليتر

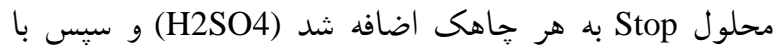

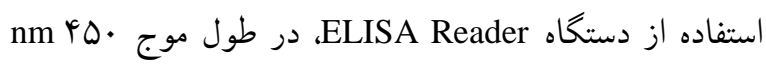
جذب نورى نمونه ها خوانده شد.

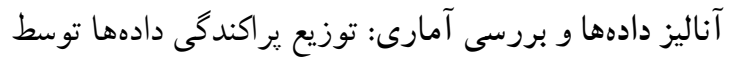

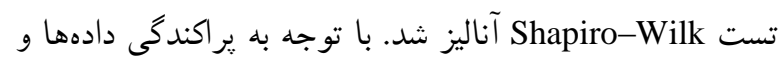

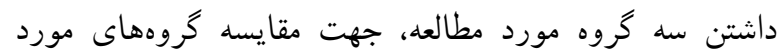

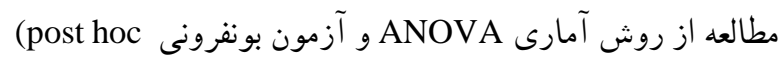

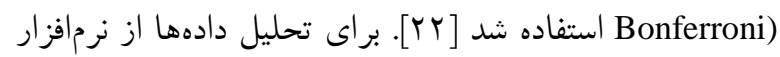

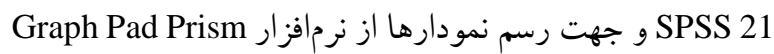

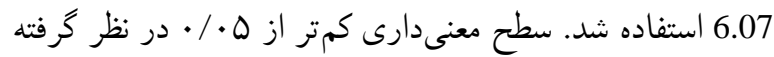

IL-1 $\beta$ (ELISA ،Biolegend, USA, Cat no: 430604) MAXтм Deluxe, Sensitivity: $0.5 \mathrm{pg} / \mathrm{mL}$, Biolegend, TNF- $\alpha$ (ELISA MAXTM USA, Cat no: 437004) Deluxe, Sensitivity: $2 \mathrm{pg} / \mathrm{mL}$, Biolegend, USA, Cat no: (430204 توسط تكنيى الايزا و بر اساس دستورالعمل كيت

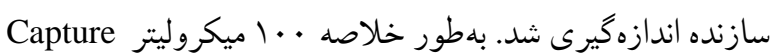
Antibody

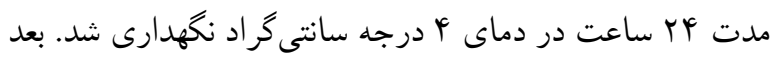

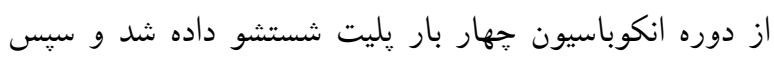

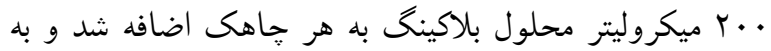

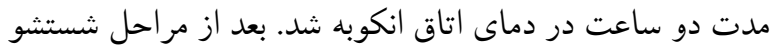

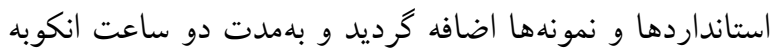

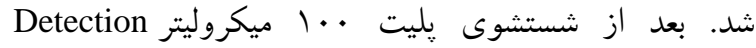

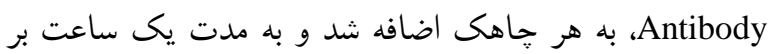

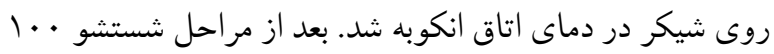

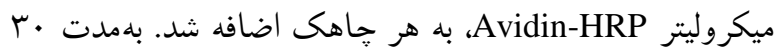

جدول ا. اطلاعات پايه افراد مورد مطالعه

\begin{tabular}{|c|c|c|c|c|}
\hline سطح معنادارى & 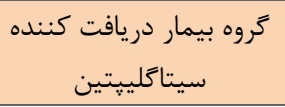 & كروه بيمار غير دريافت كننده & كروه كنترل & مشخصات \\
\hline NS & أ & ل ال به ها & 19 به 119 & جنسيت (زن به مرد) \\
\hline NS & $\mid F \wedge / r I \pm V / I \Lambda$ & $F V / \varepsilon \Delta \pm r / / F$ & $F N / A F \pm 9 / 91$ & سن (سال) \\
\hline NS & $r \varepsilon / 9 \Lambda \pm r / V I$ & $r \varepsilon|\cdot V \pm r /| \varphi \mid$ & $T F / T \pm T / 9 q$ & BMI (كيلو كرم/مترمربع) BMI \\
\hline$\leq \cdot 1 \cdot \cdot 1$ & $|r \Delta / r| \pm r \varepsilon /|| *$ & $\mid 11 / 99 \pm r q / r q *$ & $\Lambda \varepsilon / 94 \pm \varepsilon q / 9 \Lambda$ & قند ناشتاى پيلاسما (mg/dL) \\
\hline$\leq \cdot / \cdot \cdot 1$ & 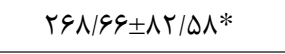 & 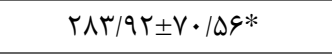 & IIT/VG $\pm \Lambda 9 / 9 T$ & قند بعد از غذاى پِلاسما(mg/dL) \\
\hline$\leq \cdot / \cdot \cdot 1$ & $V / V T \pm \cdot / \Lambda *$ & V/TrED・/AT* & $\varphi / 9 \Delta \pm \cdot / \Delta \varphi$ & $(\%) \mathrm{HbA} 1 \mathrm{c}$ \\
\hline NS & $r / T / \pm \cdot / 9 V$ & $T / F T \pm \cdot / 99$ & - & طول دوره بيمارى (سال) \\
\hline NS & $\cdot \mid \wedge 9 \pm \cdot / 1$ & $.199 \pm \cdot 114$ & $\cdot 191 \pm \cdot 119$ & كراتينين سرم ( \\
\hline NS & $V q / r \Delta \pm 1 / r V$ & $V Y / \Delta \Lambda \pm 1 / 91$ & $V F / Y \Lambda \pm I / F I$ & $\left(\mathrm{~mL} / \mathrm{min} / 1.73 \mathrm{~m}^{2}\right) \mathrm{GFR}$ \\
\hline NS & $\mid r \pm q / r$ & $\mid r / 9 \pm \Lambda / \Lambda \Delta$ & $|r / T| \pm \Delta / \Delta F$ & آلبومينورى (mg/day( \\
\hline
\end{tabular}

BMI: Body Mass Index; HbA1C: Hemoglobin A1c; GFR: Glomerular filtration rate; NS: Not Significant

$$
\text { مقادير بر حسب ميانخين土 انحراف معيار بيان شده است. "نسبت به كروه كنترل }
$$

يلاسما، HbA1c در گروههاى بيمار در مقايسه با گروه كنترل

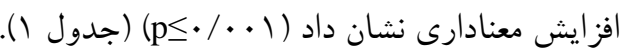

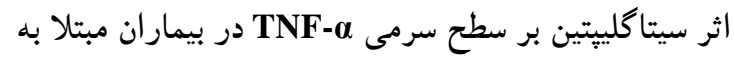
ديابت نوع دو جهت مقايسه سطح سرمى سايتوكاين التهابى TNF-

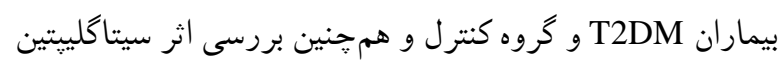

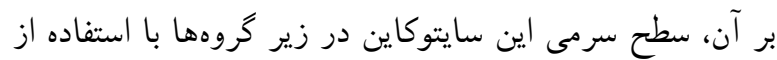

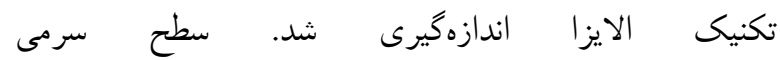
TNF- $\alpha$

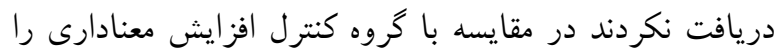

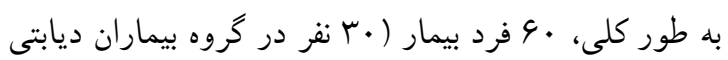
Sitagliptin+

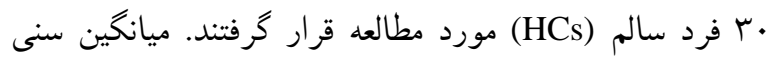

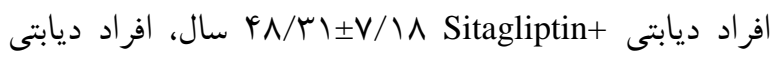

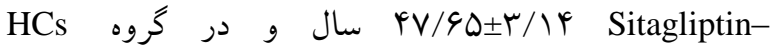
(

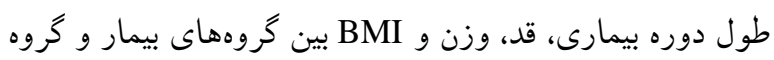

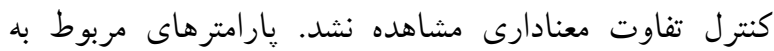
تشخيص ديابت شامل قند ناشتاى پِاسما، قند بعد از غذاى 


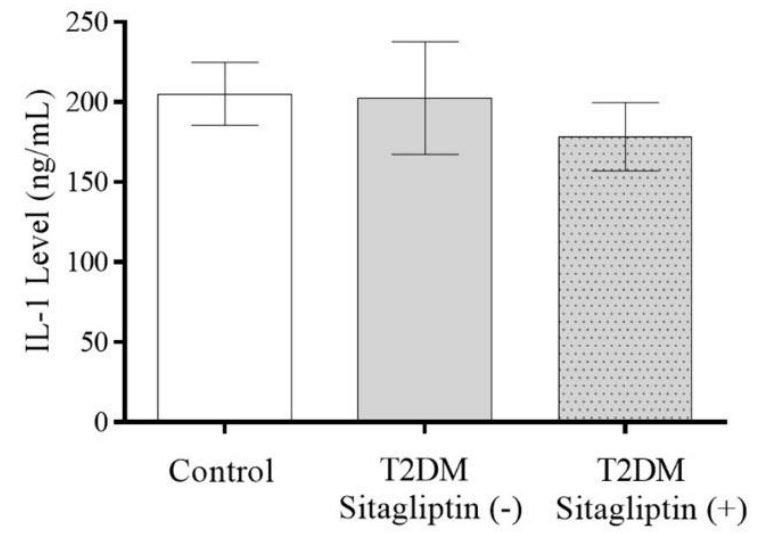

شكل r. سطح سرمى IL-1 در خروه هاى بيمار و افراد كنترل. مقايسه سطح سرمى سايتوكاين IL-1及 در گروه غير دريافت كننده سيتاگلييتين

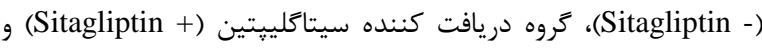

كروه كنترل (HCs). (S)

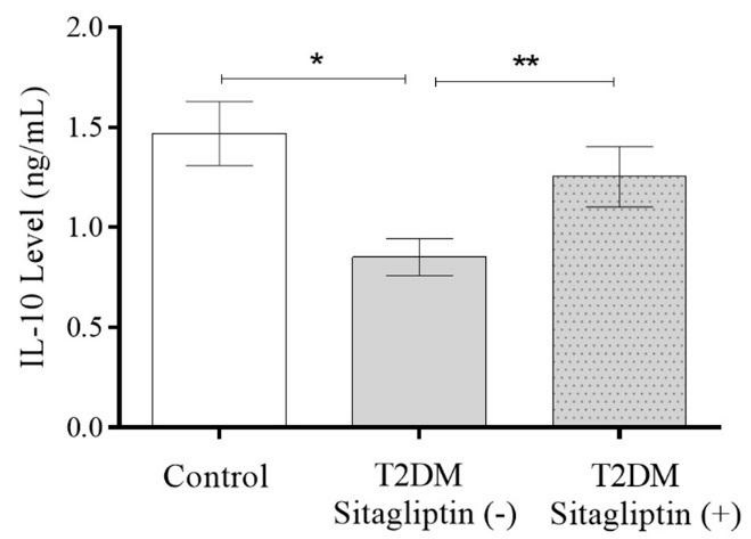

شكل r. سطح سرمى IL-10 در كروه هاى بيمار و افراد كنترل. مقايسه سطح سرمى سايتوكاين IL-10 در گروه غير دريافت كننده سيتاخليتيتين S Sitagliptin -) **روه كنترل (HCs)

\section{بحث و تتيجه َيرى}

يبشرفت التهاب در بيماران مبتلا به ديابت نوع دو ازير از عوامل

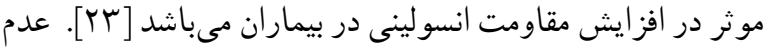
تعادل در توليد و ترشح سايتوكاينهاى التهابى و مهارى از جمله دئه

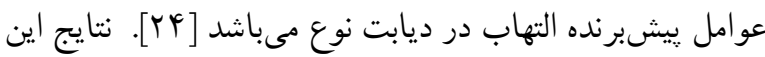

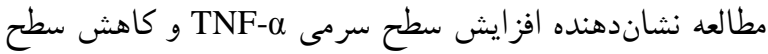
سرمى IL-10 در بيماران T2DM مىباشد. تمام بيماران در

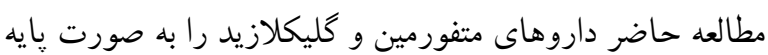

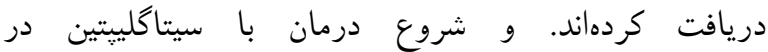

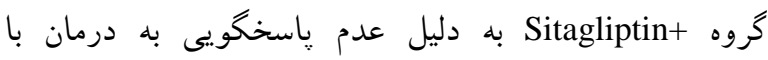

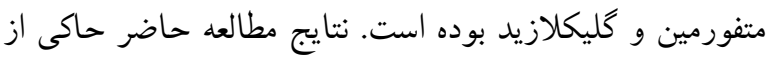
اثر كاهشى درمان با سيتاكليتين بر سطح سرمى

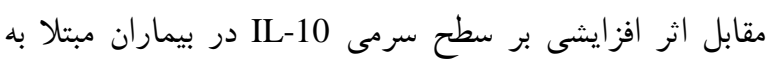
ديابت نوع دو مىباشد.

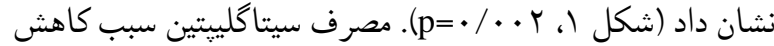

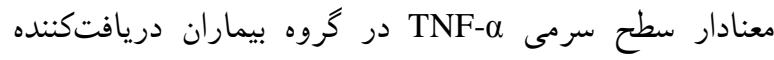

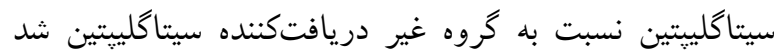

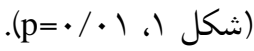

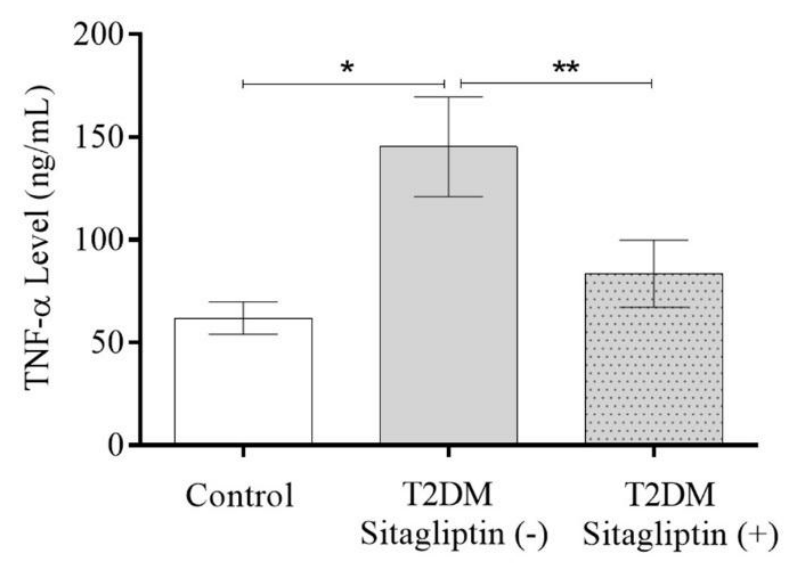

شكل ا. سطح سرمى TNF-

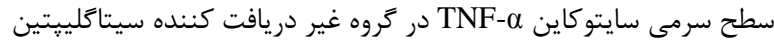

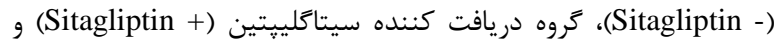
* F*

اثر سيتا كليتيتين بر سطح سرمى IL-1及 در بيماران مبتلا به ديابت نوع دو

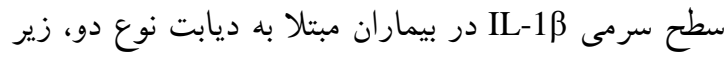

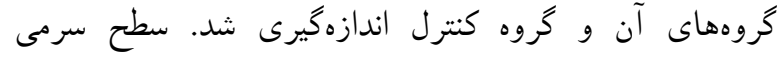

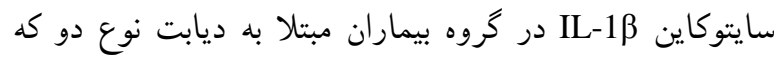

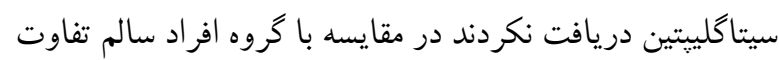

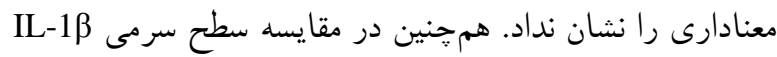

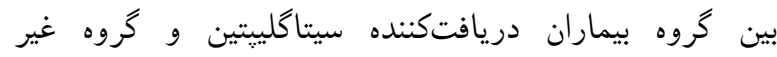
دريافتكننده سيتاكليتين تفاوت معنادارى مشاهده نشد (شكل

اثر سيتا كلييتين بر سطح سرمى IL-10 در بيماران مبتلا به ديابت نوع دو

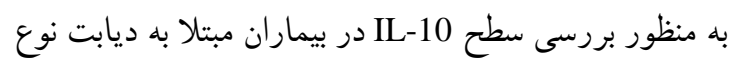

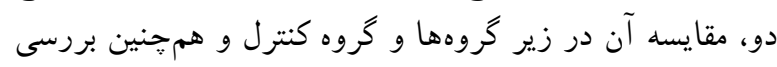

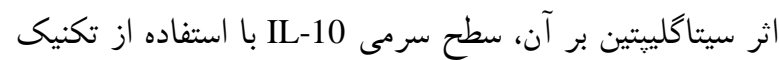

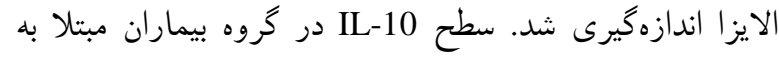

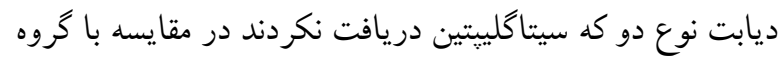

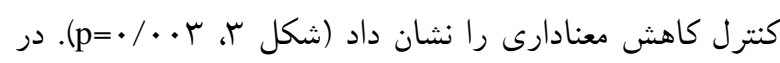

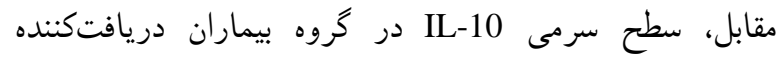
سيتاكليبتين نسبت به كروه غير دريافتكننده سيتاكليبتين افزايش

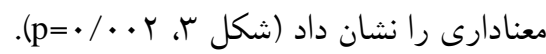




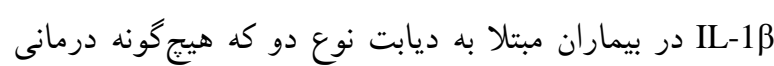

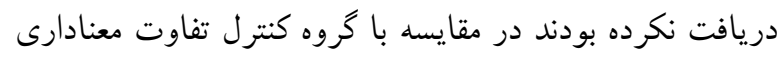

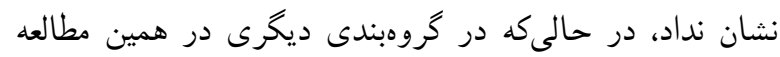

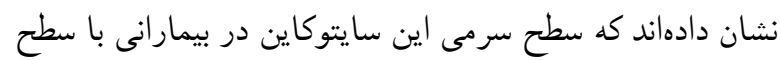

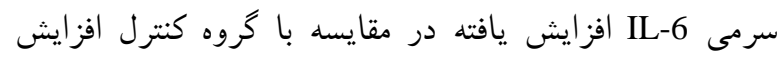

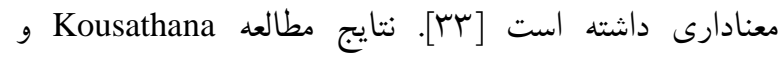

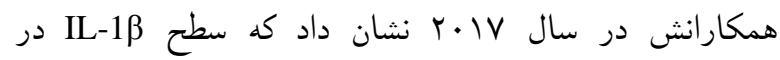

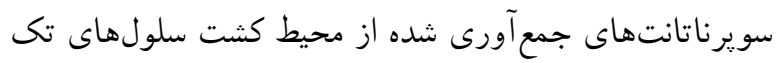

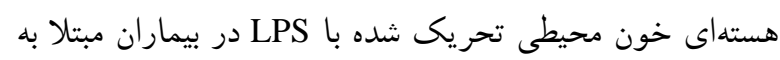

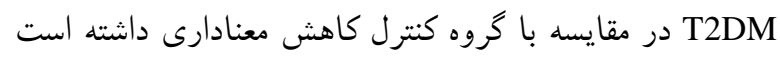

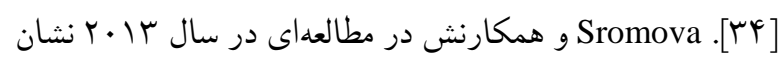

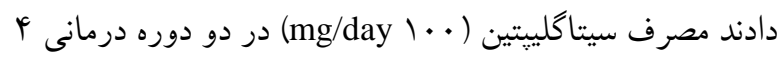

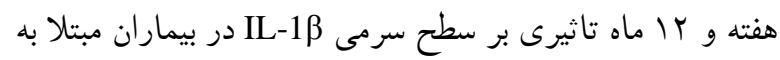

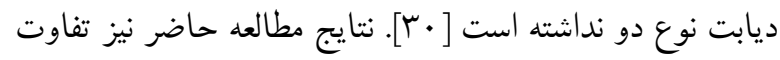

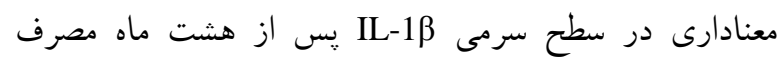

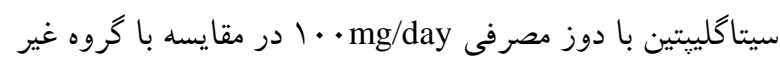
دريافتكنده سيتاكليبتين نشان نداد.

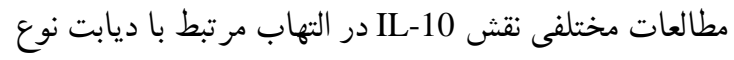
دو و همجنين ارتباط بين سطوح IL-10 توليدى و تنظيم ميزان

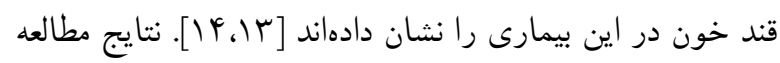
Francisco توليدى توسط سلولهاى T كمكى TL-10

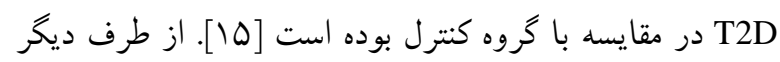

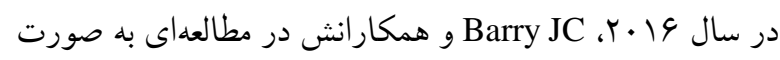

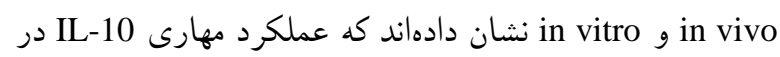

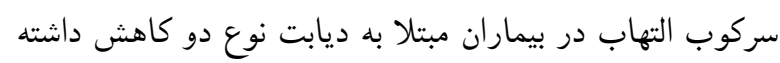

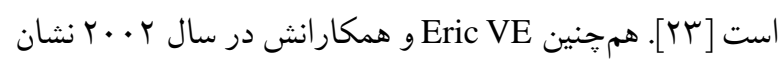

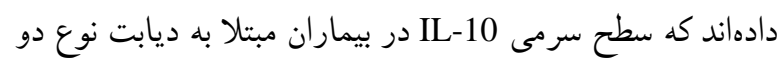

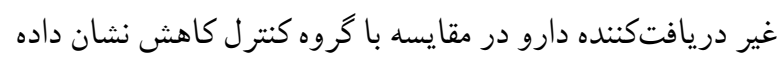

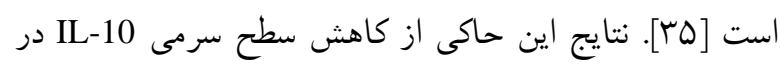

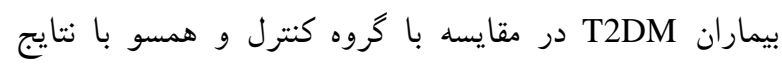
مطالعات سرمى مىباشد. نتايج مطالعه Satoh-Asahara N و همكار انش روى بيماتش سيماران

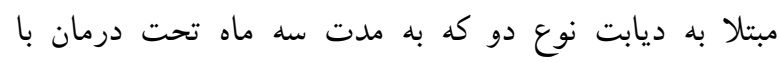

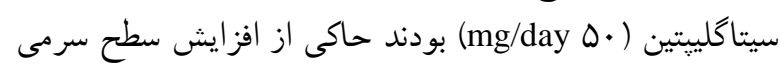
دL-10

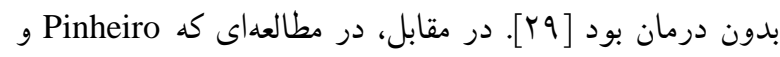

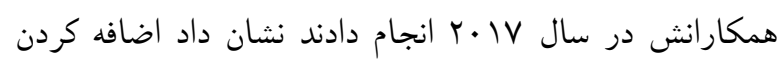

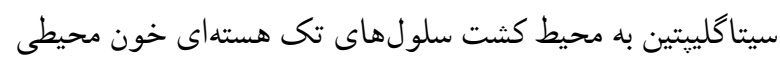

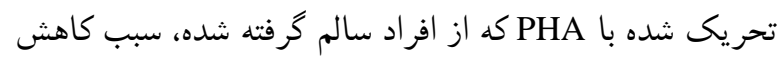
توليد IL-10 توسط اين سلولها مىشود [عَّ]. نتايج اين مطالعه
بر اساس مطالعات انجام شده TNF-

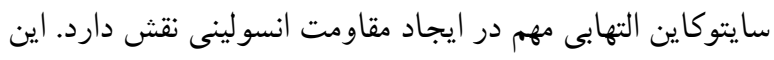

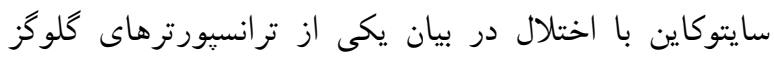

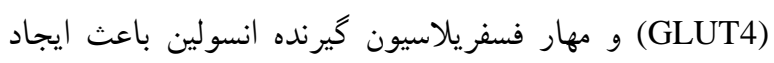

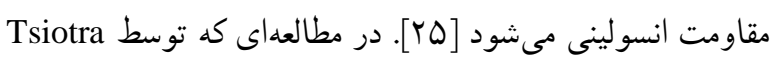

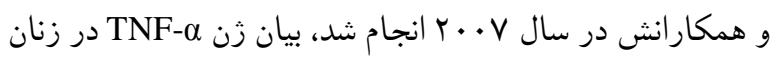

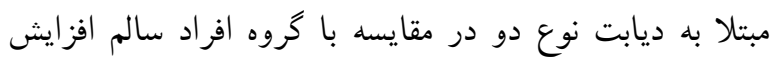

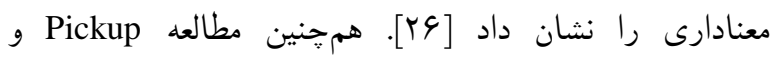

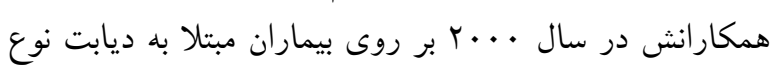

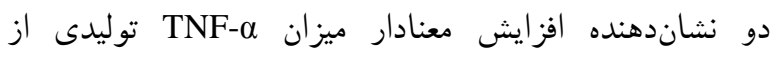

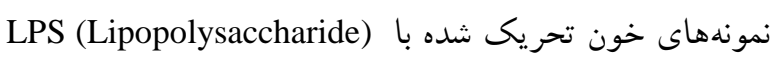

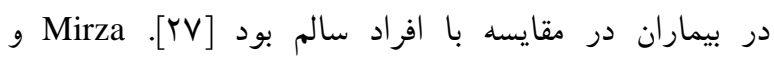

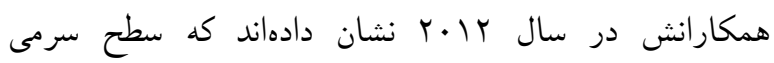
TNF- $\alpha$

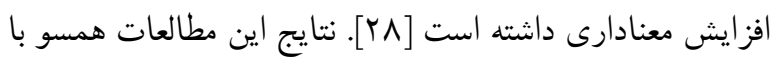

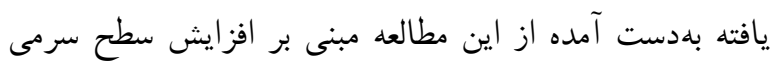
TNF- $\alpha$ در ارتباط با اثرات ضد التهابى احتمالى سيتاكليبينين، نتايج

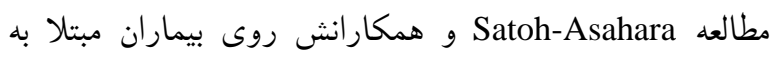

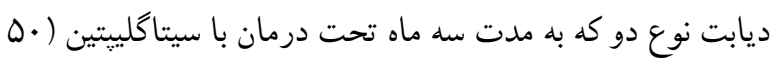
(mg/day بودند حاكى از كاهش سطح دمFبيان زن TNF-

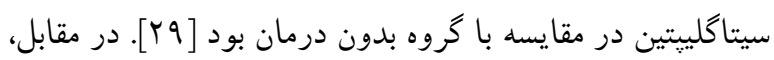

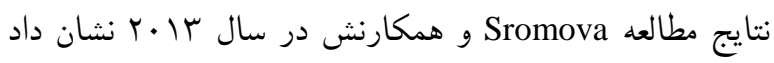
كه مصرف سيتاگليبيتن (... هفته و Ir الماه تاثيرى بر سطح سرمى TNF-

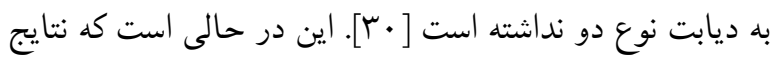

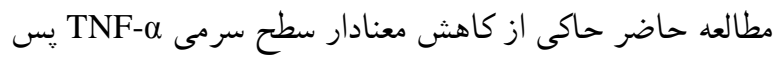

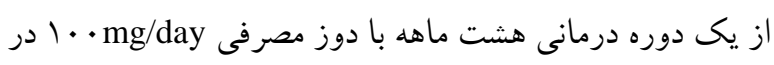

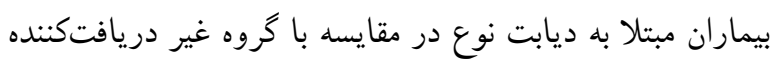

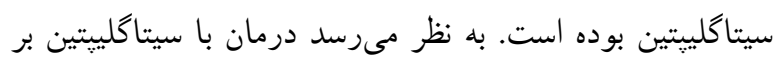

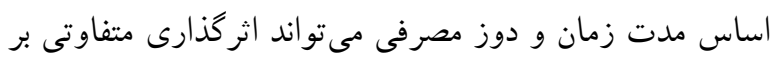
ميزان سايتوكاينها نشان دهد.

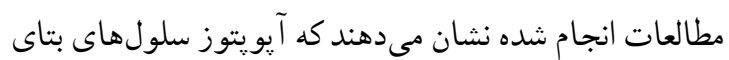

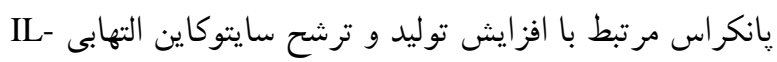

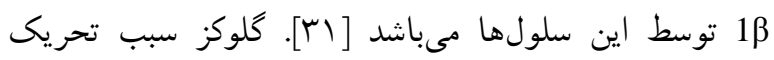

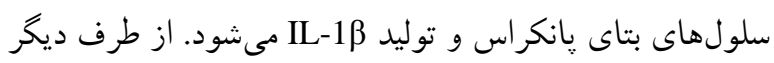

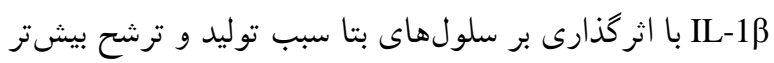

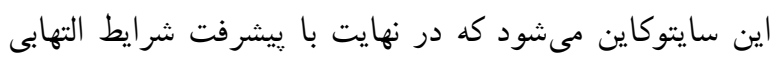

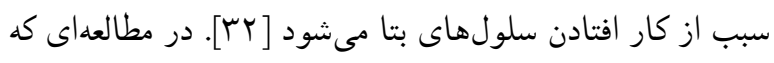
Spranger 
تشكر و قدرداتى

اين مقاله برگرفته از طرح تحقيقاتى هيئت علمى به شماره

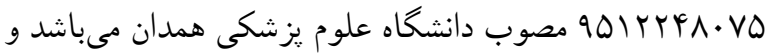
با حمايت مالى معاونت محترم تحقيقات و فناورى دانشگاه به

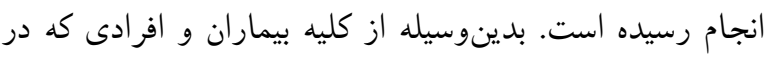

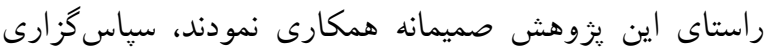
مىشود.

\section{منابع}

[1] Sheikh V, Zamani A, Mahabadi-Ashtiyani E, Tarokhian H, Borzouei S, Alahgholi-Hajibehzad M. Decreased regulatory function of CD4(+)CD25(+)CD45RA(+) T cells and impaired IL-2 signalling pathway in patients with type 2 diabetes mellitus. Scand J Immunol 2018; 88: e12711.

[2] Borzouei S, Sheikh V, Ghasemi M, Zamani A, Telikani Z, Zareighane $\mathrm{Z}$, et al. Anti-Inflammatory Effect of Combined Sitagliptin and Vitamin D3 on Cytokines Profile in Patients with Type 2 Diabetes Mellitus. J Interferon Cytokine Res 2019; 39: 293301.

[3] Donath MY, Shoelson SE. Type 2 diabetes as an inflammatory disease. Nat Rev Immunol 2011; 11: 98-107.

[4] Wang C, Guan Y, Yang J. Cytokines in the Progression of Pancreatic beta-Cell Dysfunction. Int J Endocrinol 2010; 2010: 515136.

[5] Gregor MF, Hotamisligil GS. Inflammatory mechanisms in obesity. Ann Rev Immunol 2011; 29: 415-445.

[6] Pickup JC. Inflammation and activated innate immunity in the pathogenesis of type 2 diabetes. Diabetes Care 2004; 27: 813-823.

[7] Navarro-Gonzalez JF, Mora-Fernandez C. The role of inflammatory cytokines in diabetic nephropathy. J Am Soc Nephrol 2008; 19: 433-442.

[8] Dinarello CA, Donath MY, Mandrup-Poulsen T. Role of IL1 beta in type 2 diabetes. Curr Opin Endoc Diabetes Obes 2010; 17 : 314-321.

[9] Alahgholi-Hajibehzad M, Oflazer P, Aysal F, Durmus H, Gulsen-Parman Y, Marx A, et al. Regulatory function of $\mathrm{CD} 4+\mathrm{CD} 25++\mathrm{T}$ cells in patients with myasthenia gravis is associated with phenotypic changes and STAT5 signaling: 1,25Dihydroxyvitamin D3 modulates the suppressor activity. J Neuroimmunol 2015; 281: 51-60.

[10] Alahgholi-Hajibehzad M, Kasapoglu P, Jafari R, Rezaei N. The role of T regulatory cells in immunopathogenesis of myasthenia gravis: implications for therapeutics. Exp Rev Clin Immunol 2015; 11: 859-870.

[11] Alahgholi-Hajibehzad M, Durmus H, Aysal F, GulsenParman Y, Oflazer P, Deymeer F, et al. The effect of interleukin (IL) 21 and CD4(+) CD25(++) T cells on cytokine production of CD4(+) responder $\mathrm{T}$ cells in patients with myasthenia gravis. Clin Exp Immunol 2017; 190: 201-207.

[12] Sheikh V, Kasapoglu P, Zamani A, Basiri Z, TahamoliRoudsari A, Alahgholi-Hajibehzad M. Vitamin D3 inhibits the proliferation of T helper cells, downregulate $\mathrm{CD} 4(+) \mathrm{T}$ cell cytokines and upregulate inhibitory markers. Human Immunol 2018; 79: 439445 .

[13] Gao M, Zhang C, Ma Y, Bu L, Yan L, Liu D. Hydrodynamic delivery of mIL10 gene protects mice from high-fat diet-induced obesity and glucose intolerance. Mol Ther 2013; 21: 1852-1861.

[14] Hong EG, Ko HJ, Cho YR, Kim HJ, Ma Z, Yu TY, et al. Interleukin-10 prevents diet-induced insulin resistance by attenuating macrophage and cytokine response in skeletal muscle. Diabetes 2009; 58: 2525-2535.

[15] Francisco CO, Catai AM, Moura-Tonello SC, Arruda LC, Lopes SL, Benze BG, et al. Cytokine profile and lymphocyte subsets in type 2 diabetes. Braz J Med Biol Res 2016; 49: e5062.

[16] Jagannathan-Bogdan M, McDonnell ME, Shin H, Rehman $\mathrm{Q}$, Hasturk $\mathrm{H}$, Apovian $\mathrm{CM}$, et al. Elevated proinflammatory cytokine production by a skewed $\mathrm{T}$ cell compartment requires monocytes and promotes inflammation in type 2 diabetes. J Immunol 2011; 186: 1162-1172.
نشان داد كه مصرف هشت ماه سيتاكليبتين با دوز مصرفى mg/day · • سبب كاهش سطح سرمى IL-10 در بيماران مبتلا به ديابت نوع در مقايسه با گروه غير دريافتكننده

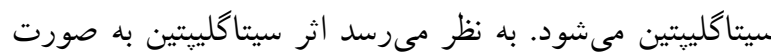
مصرف خوراكى و يا اثر مستقيم آن بر سلولها مى تواند نتايج

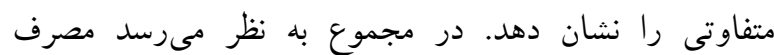
سيتاگلييتين با توجه به دوز و طول دوره مصرف مىتواند اثر گذارى متفاوتى نشان دهد. نتايج اين مطالعه حاكى از افزايش سطح سرمى

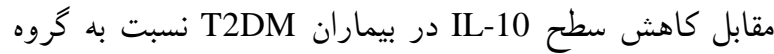
كنترل بود كه نشاندهنده عدم تعادل در توليد سايتوكاينهاى بهاي التهابى و مهارى در بيماران T2DM (يروفايل التهابى) مىباشد. سيتاكليتين با جلوگيرى از غير فعال شدن هورمونهاى اينكريتين سبب كاهش غلظت كلوكز خون مىشود و به عنوان

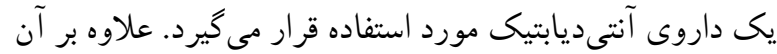
مطالعه حاضر نشاندهنده اثرات ضد التهابى مصرف سيتاكليتين

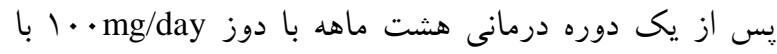
كاهش سطح سرمى سايتوكاين التهابى سايتوكاين مهارى IL-10 در بيماران T2DM بود. نتايج اين مطالعه نشان داد كه تجويز سيتاكليتين باعث كاهث موثر التهاب

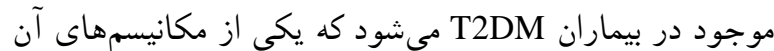
مىتواند تاثير بر تعادل سايتوكاينهاى سيستم ايمنى بدن باشد كه در اين مطالعه نشان داده شد. محدوديت هاى يثروهش:

اين مطالعه با توجه به جمعيت نه جندان زياد در بيماران ديابتى نوع دو مورد بررسى صورت گرفت. به نظر مىرسد

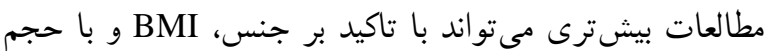
نمونه بيثتر انجام گيرد. همجنين بررسى بر بر روى زيركروههاى

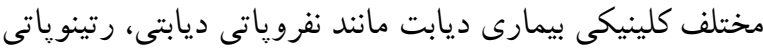

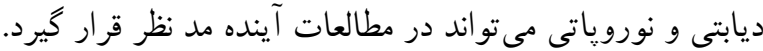

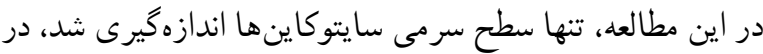

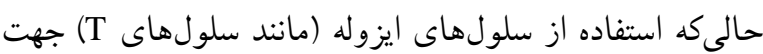

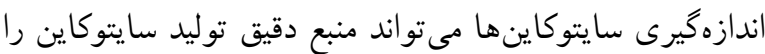

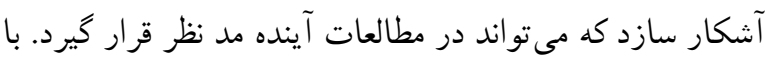
توجه به اثرگذارىهاى متفاوت سيتاگلييتين بر اساس دورهو دوز دوز مصرفى، در نظر گرفتن دوزها و دورههاى مصرف مرف متفاوت

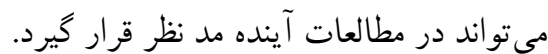


alpha, IL-6 and adiponectin and low levels of leptin in a population of Mexican Americans: a cross-sectional study. Cytokine 2012; 57 : 136-142.

[29] Satoh-Asahara N, Sasaki Y, Wada H, Tochiya M, Iguchi A, Nakagawachi R, et al. A dipeptidyl peptidase-4 inhibitor, sitagliptin, exerts anti-inflammatory effects in type 2 diabetic patients. Metabolism 2013; 62: 347-351.

[30] Sromova L, Busek P, Mareckova H, Andel M, Sedo A. The effect of dipeptidyl peptidase-IV inhibitor sitagliptin on the immune functions in patients with type 2 diabetes. Frontiers in Immunology 2013.02.00154..

[31] Maedler K, Sergeev P, Ris F, Oberholzer J, Joller-Jemelka HI, Spinas GA, et al. Glucose-induced beta cell production of IL1 beta contributes to glucotoxicity in human pancreatic islets. J Clin Invest 2002; 110: 851-860.

[32] Zhao G, Dharmadhikari G, Maedler K, Meyer-Hermann M. Possible Role of Interleukin-1 $\beta$ in Type 2 Diabetes Onset and Implications for Anti-inflammatory Therapy Strategies. PLoS Comput Biol 2014; 10: e1003798.

[33] Spranger J, Kroke A, Mohlig M, Hoffmann K, Bergmann MM, Ristow M, et al. Inflammatory cytokines and the risk to develop type 2 diabetes: results of the prospective population-based European Prospective Investigation into Cancer and Nutrition (EPIC)-Potsdam Study. Diabetes 2003; 52: 812-817.

[34] Kousathana F, Georgitsi M, Lambadiari V, GiamarellosBourboulis EJ, Dimitriadis G, Mouktaroudi M. Defective production of interleukin-1 beta in patients with type 2 diabetes mellitus: Restoration by proper glycemic control. Cytokine 2017; 90: 177-184.

[35] van Exel E, Gussekloo J, de Craen AJ, Frolich M, BootsmaVan Der Wiel A, Westendorp RG. Low production capacity of interleukin-10 associates with the metabolic syndrome and type 2 diabetes: the Leiden 85-Plus Study. Diabetes 2002; 51: 1088-1092.

[36] Pinheiro MM, Stoppa CL, Valduga CJ, Okuyama CE, Gorjao R, Pereira RM, et al. Sitagliptin inhibit human lymphocytes proliferation and Th1/Th17 differentiation in vitro. Eur J Pharm Sci 2017; 100: 17-24.
[17] Zeng C, Shi X, Zhang B, Liu H, Zhang L, Ding W, et al. The imbalance of Th17/Th1/Tregs in patients with type 2 diabetes: relationship with metabolic factors and complications. J Mol Med (Berlin, Germany) 2012; 90: 175-186.

[18] Correia S, Carvalho C, Santos MS, Seica R, Oliveira CR, Moreira PI. Mechanisms of action of metformin in type 2 diabetes and associated complications: an overview. Mini Rev Med Chem 2008; 8: 1343-1354.

[19] Plosker GL. Sitagliptin: a review of its use in patients with type 2 diabetes mellitus. Drugs 2014; 74: 223-242.

[20] Sromova L, Busek P, Posova H, Potockova J, Skrha P, Andel M, et al. The effect of dipeptidyl peptidase-IV inhibition on circulating $\mathrm{T}$ cell subpopulations in patients with type 2 diabetes mellitus. Diabetes Res Clin Pract 2016; 118: 183-192.

[21] Tremblay AJ, Lamarche B, Deacon CF, Weisnagel SJ, Couture P. Effects of sitagliptin therapy on markers of low-grade inflammation and cell adhesion molecules in patients with type 2 diabetes. Metabolism 2014; 63: 1141-1148.

[22] Telikani Z, Sheikh V, Zamani A, Borzouei S, Salehi I, Amirzargar MA, et al. Effects of sitagliptin and vitamin D3 on T helper cell transcription factors and cytokine production in clinical subgroups of type 2 diabetes mellitus: highlights upregulation of FOXP3 and IL-37. Immunopharmacol Immunotoxicol 2019; 41: 113.

[23] Barry JC, Shakibakho S, Durrer C, Simtchouk S, Jawanda KK, Cheung ST, et al. Hyporesponsiveness to the anti-inflammatory action of interleukin-10 in type 2 diabetes. Sci Rep 2016; 6: 21244.

[24] Donath MY, Shoelson SE. Type 2 diabetes as an inflammatory disease. Nat Rev Immunol 2011; 11: 98.

[25] Akash MSH, Rehman K, Liaqat A. Tumor Necrosis FactorAlpha: Role in Development of Insulin Resistance and Pathogenesis of Type 2 Diabetes Mellitus. J Cell Biochem 2018; 119: 105-110.

[26] Tsiotra PC, Tsigos C, Yfanti E, Anastasiou E, Vikentiou M, Psarra K, et al. Visfatin, TNF-alpha and IL-6 mRNA expression is increased in mononuclear cells from type 2 diabetic women. Horm Metab Res 2007; 39: 758-763.

[27] Pickup JC, Chusney GD, Thomas SM, Burt D. Plasma interleukin-6, tumour necrosis factor $\alpha$ and blood cytokine production in type 2 diabetes. Life Sci 2000; 67: 291-300.

[28] Mirza S, Hossain M, Mathews C, Martinez P, Pino P, Gay $\mathrm{JL}$, et al. Type 2-diabetes is associated with elevated levels of TNF- 


\title{
Effect of sitagliptin on serum levels of TNF- $\alpha$, IL-1 $\beta$ and IL-10 in patients with type 2 diabetes mellitus
}

\author{
Zahra Telikani (M.Sc) ${ }^{1,2}$, Vida Sheikh (M.D) ${ }^{3}$, Alireza Zamani (Ph.D) ${ }^{1,2}$, Shiva Borzouei (M.D) ${ }^{3}$, Iraj Salehi (Ph.D) ${ }^{4}$ \\ Mohammad Ali Amirzargar (M.D) ${ }^{3}$, Mahdi Alahgholi-Hajibehzad (Ph.D) ${ }^{* 1,2}$ \\ 1 - Dept. of Immunology, School of Medicine, Hamadan University of Medical Sciences, Hamadan, Iran \\ 2 - Molecular Immunology Research Group, Research Center for Molecular Medicine, Hamadan University of Medical Sciences, Hamadan, Iran \\ 3- Dept. of Internal Medicine, School of Medicine, Hamadan University of Medical Sciences, Hamadan, Iran \\ 4- Neurophysiology Research Center, Hamadan University of Medical Sciences, Hamadan, Iran
}

* Corresponding author. +98 8118380583 m.hajibehzad@umsha.ac.ir

Received:6 Feb 2019; Accepted:17 Jun 2019

Introduction: Type 2 diabetes mellitus (T2DM) is an inflammatory disease with alterations in immune system. Remarkably, cytokine imbalance plays an important role in pathogenesis of T2DM. The purpose of this study was to determine the serum levels of TNF- $\alpha$, IL-1 $\beta$ and IL-10 and the effects of sitagliptin on the level of these cytokines in patients with T2DM.

Materials and Methods: Blood samples were collected from 60 T2DM patients and 30 healthy control subjects (HCs). T2DM patients were divided into two subgroups based on their treatment; with sitagliptin treatment (100 $\mathrm{mg} /$ day, $\mathrm{n}=30$ ) for 8 months and without sitagliptin treatment $(\mathrm{n}=30)$. The serum levels of TNF- $\alpha$, IL-1 $\beta$ and IL-10 cytokines were assessed using ELISA method. ANOVA with posthoc Bonferroni were applied to statistical analysis.

Results: The serum level of TNF- $\alpha$ was significantly higher in T2DM patients without sitagliptin compared to HCs $(p=0.002)$. Whereas, the serum level of TNF- $\alpha$ was significantly lower in patients with sitagliptin compared to patients without sitagliptin $(\mathrm{p}=0.01)$. The serum level of IL-10 showed a significant reduction in patients without sitagliptin compared to HCs ( $\mathrm{p}=0.003)$. On the other hand, a significant elevation was observed in serum level of IL10 between T2DM patients with and without sitagliptin $(\mathrm{p}=0.002)$. Considerably, no significant difference was observed in serum level of IL-1 $\beta$ between T2DM patients with and without sitagliptin and also in comparison to HCs.

Conclusion: Sitagliptin treatment significantly decreased the level of pro-inflammatory TNF- $\alpha$ and increased antiinflammatory IL-10 in T2DM patients. It seems that sitagliptin had an anti-inflammatory effect on immune system of the patients.

Keywords: Diabetes Mellitus Type 2, Cytokines, Sitagliptin Phosphate, TNF- $\alpha$, Interleukin-1, Interleukin-10. 